\title{
ARTIGOS
}

\section{FORMAS POSSÍVEIS DE SER NAS POLÍTICAS LINGUÍSTICAS DE EDUCAÇÃO DE SURDOS EM PORTUGAL*}

\author{
Pedro Henrique Witchs ${ }^{1}$ (1) \\ Maura Corcini Lopes ${ }^{2}$ (1) \\ Orquídea Coelho ${ }^{3}$
}

\begin{abstract}
RESUMO: O artigo analisa um conjunto de políticas linguísticas de educação de surdos para mostrar como saberes sobre a surdez se articulam a normativas de comportamentos linguísticos dos surdos e operam na constituição de formas possíveis de ser surdo na contemporaneidade. A análise utiliza, como um exemplo destacado, documentos legais que regulamentam a educação de surdos em Portugal. Nesses documentos, percebem-se recorrências discursivas que permitem pensar a produção de formas universais possiveis de ser surdo governáveis principalmente pelo uso da língua, seja ela de sinais, seja oral. Essas formas de ser podem ser pensadas para além de um território geográfico, uma vez que se inspiram em saberes e tendências internacionais da educaçáo de surdos.
\end{abstract}

Palavras-chave: Educação de surdos. Políticas linguísticas. Portugal. Governamento. Subjetivação.

\section{PosSible WAYS OF BEING IN THE LINGUISTIC POLiCies OF DEAF EDUCATION IN PORTUGaL}

ABSTRACT: The article analyzes a set of linguistic policies of deaf education to show how knowledge about deafness articulates to the norms of deaf behavior and operates in the constitution of possible forms of being deaf in the contemporaneity. The analysis uses, as a prominent example, legal documents that regulate deaf education in Portugal. It is

\footnotetext{
*Este artigo é resultado do projeto de pesquisa Politicas linguísticas de educação de surdos no Brasil e em Portugal, financiado pela Coordenação de Aperfeiçoamento de Pessoal de Nível Superior (CAPES), e conta com o apoio de bolsa de Produtividade em Pesquisa do Conselho Nacional de Desenvolvimento Científico e Tecnológico (CNPq).

${ }^{1}$ Universidade Federal do Espírito Santo, Departamento de Línguas e Letras, Programa de Pós-Graduação em Linguística - Vitória (ES), Brasil. E-mail: pedro.witchs@ufes.br

${ }^{2}$ Universidade do Vale do Rio dos Sinos, Escola de Humanidades, Programa de Pós-Graduação em Educação - São Leopoldo (RS), Brasil. E-mail: maura@unisinos.br

${ }^{3}$ Universidade do Porto, Faculdade de Psicologia e de Ciências da Educação, Centro de Investigação e Intervenção Educativas (CIIE) - Porto, Portugal. E-mail: orquidea@fpce.up.pt DOI: 10.1590/ES0101-73302019202053
} 
observed, in the documents, discursive recurrences that allow to think of the production of possible universal forms of being deaf that are mainly governed by the use of the language, be it signed or spoken. These forms of being can be thought beyond a geographical territory, since they are inspired by international knowledge and tendencies of deaf education.

Keywords: Deaf education. Language policies. Portugal. Government. Subjectivation.

\section{FORMAS POSIBLES DE SER EN LAS POLÍTICAS LINGÜÍSTICAS DE EDUCACIÓN DE SORDOS EN PORTUGAL}

RESUMEN: El artículo analiza un conjunto de políticas lingüísticas de educación de sordos para mostrar cómo saberes sobre la sordera se articulan las normativas de comportamientos lingüísticos de los sordos y operan en la constitución de formas posibles de ser sordo en la contemporaneidad. El análisis utiliza, como un ejemplo prominente, documentos legales que regulan la educación de sordos en Portugal. En estos documentos, se percibe recurrencias discursivas que permiten pensar la producción de formas universales posibles de ser sordo gobernables principalmente por el uso de la lengua, sea de signos u oral. Estas formas de ser pueden ser pensadas más allá de un territorio geográfico, pues se inspiran en saberes y tendencias internacionales de la educación de sordos.

Palabras clave: Educación de sordos. Políticas lingüísticas. Portugal. Gobernamento. Subjetividad.

\section{Introdução}

A

o estudar as relações entre línguas e sociedades, Burke (1995) destaca a língua como uma forma de poder: um meio pelo qual é possível controlar ou resistir a um controle; mudar ou impedir mudanças; afirmar ou suprimir formas de ser. Isso implica entender a constituição da língua oficial como um instrumento para a consolidação de identidades nacionais ao longo da história da formação dos estados-naçóes. Nesse contexto, a escola tem um papel fundamental; ela é a instituição que tem a missão de "nacionalizar filhos de estrangeiros ou os falantes de dialetos ou línguas diferentes da institucionalizada como 'língua nacional'” (BERENBLUM, 2003, p. 85).

No caso de pessoas surdas, o ensino da língua nacional tem servido, dentre outras finalidades, também para um propósito nacionalizador, sobretudo quando o uso da língua de sinais se configura como um problema educacional e é 
alvo de debates históricos. Ao considerar esses aspectos para discutir a educação de surdos na articulação com suas políticas linguísticas, é possível pensar a constituição de formas de ser surdo a partir de sua correlação entre saberes sobre a surdez e normativas do comportamento linguístico dos surdos - três eixos que constituem uma matriz de experiência (FOUCAULT, 2010). Neste artigo, apresentamos uma análise, na perspectiva da surdez entendida como uma matriz de experiência, a partir de um conjunto de documentos legais que regulamentam políticas linguísticas de educação de surdos em Portugal - um exemplo destacado que abrange uma tendência internacional em educação de surdos.

Após esta breve introdução, definimos o entendimento da surdez como uma matriz de experiência (FOUCAULT, 2010) e apresentamos os conceitos de governamento linguístico e subjetivação; em seguida, desenvolvemos a análise dos documentos legais que regulamentam políticas linguísticas de educação de surdos em Portugal, tais como o Decreto-Lei no 319/91 (PORTUGAL, 1991), o Despacho $n^{\circ}$ 7.520/98 (PORTUGAL, 1998), o Decreto-Lei no 3/2008 (PORTUGAL, 2008a), a Lei no 21/2008 (PORTUGAL, 2008b) e os mais recentes Decretos-Leis no 54/2018 e 55/2018 (PORTUGAL, 2018a; 2018b). Identificamos, no conjunto analisado, um forte acento na preocupação educativa em causar benefícios e evitar prejuízos na formação escolar de surdos, tendo, como critério básico, especificidades da cultura e conduta linguística desses sujeitos.

Ao tomarmos o conceito de surdez como uma matriz de experiência, entendemos que os documentos ou as normativas analisadas refletem tendências discursivas mundiais sobre as formas de ler, interpretar e conduzir a conduta linguística dos sujeitos surdos. Percebemos que as semelhanças entre práticas e interpretaçóes feitas sobre os surdos, em diferentes países, conduzem tais sujeitos a serem de determinadas maneiras. Dito de outra forma, as possibilidades de ser dos sujeitos surdos, asseguradas nas normativas, se tornam bastante restritivas e homogeneizadoras das diferenças subjetivas de tais sujeitos.

\section{Surdez como matriz de experiência}

Ao considerar aspectos da constituiçáo dos sujeitos, entendemos a surdez como uma forma histórica de subjetivação, o que Foucault (2010) conceituou como uma experiência. Para o autor, a subjetivação é o processo pelo qual é possível obter "a constituiçâo de um sujeito, mais precisamente de uma subjetividade, que [...] não passa de uma das possibilidades dadas de organização de uma consciência de si" (FOUCAULT, 2006, p. 262). Para analisar o que ele entendeu como focos ou matrizes de experiência, o autor definiu a correlação de três eixos que constituem a experiência: o eixo da formaçáo de saberes, o eixo da normatividade dos comportamentos e o eixo dos modos de ser do sujeito (FOUCAULT, 2010). A surdez também pode ser pensada como matriz de experiência se analisa- 
da na correlação entre a formação de saberes sobre a surdez, a normatividade dos comportamentos dos surdos e os seus modos de ser (WITCHS; LOPES, 2015b). Em estudo realizado no Brasil no qual a surdez foi analisada como uma matriz de experiência, observou-se que o

empenho para incutir uma identidade nacional na subjetividade dos surdos que viviam no Brasil na primeira metade do século 20 foi possível a partir da formação de uma série de saberes sobre a surdez e sobre os surdos, articulada às normativas dos comportamentos desses sujeitos (WITCHS; LOPES, 2015a, p. 183).

Assim, assumimos que a subjetividade atrelada às formas de ser surdo possa ser imanente a uma questáo da diferença linguística. Sobretudo porque os primeiros esforços educacionais voltados para os surdos aconteceram na direção de ensinar-lhes uma língua, preferencialmente a língua oral. Mesmo quando o uso da língua de sinais lhes era permitido no passado, ela servia como um meio para alcançar um fim: a oralidade.

A partir do século XVIII, a surdez se tornou um ponto de fascinação, sobretudo porque, a partir dela, se discutia sobre a existência e a função da linguagem (DAVIS, 1995). Por volta desse período foram publicados os primeiros e principais textos sobre a surdez, tais como Discourse on Deafness and Speechlessness, do médico alemão Solomon Alberti, em 1591; L'arte dc' cenni, do italiano Giovanni Bonifacio, em 1616; Reduction de las letras y Arte de enseñar á ablar los Mudos, do espanhol Juan Pablo Bonet, em 1620; dentre outros que permearam a emergência da educação de surdos e subsidiaram o trabalho de educadores em prol do ensino da língua oral para surdos.

$\mathrm{Na}$ medida em que se tornou escolarizada, a educação de surdos não perdeu o seu foco na instrução da língua e até o aprimorou. Foram criadas diferentes abordagens metodológicas de ensino, focadas no uso da língua pelos surdos, assim como também começaram a circular, pelo campo, conflitos filosóficos a elas relacionados, que perduram até hoje. Para Dizeu e Caporali (2005), as diferentes modalidades linguísticas utilizadas pelos surdos não podem ser analisadas sob um ponto de vista que as compara como inferior ou superior. Sobre essa questão, as autoras declaram:

A discussão gestualismo versus oralidade ocorre desde os primórdios da educação de surdos. Se tomarmos como exemplo países que têm sistemas de saúde e de educação mais avançados, como Suécia, Dinamarca, Noruega, Holanda e até mesmo Estados Unidos da América, as discussóes sobre a surdez e o baixo alcance educacional dos surdos também são polêmicas (DIZEU; CAPORALI, 2005, p. 585-586). 
A constituição de alguns modos de ser surdo, portanto, passa a acontecer na e pela escola: é nessa instituição que são regulados os usos que os surdos fazem da língua, bem como as línguas das quais devem fazer tal uso. Com a responsabilidade de agir sob a ação dos alunos, tendo em vista criar mudanças nos seus comportamentos, a escola se torna, por excelência, uma instituição conveniente ao governamento, que opera sobre um campo de possibilidades que permite a regulação do comportamento dos sujeitos. Na condição de um conjunto de açóes sobre as açóes possíveis, o governamento compreende a condução das condutas, sendo a conduta, no conjunto da obra foucaultiana, "o termo que permite captar melhor a especificidade das relaçóes de poder" (CASTRO, 2009, p. 327). Para Foucault (2008, p. 255), a conduta é "a atividade que consiste em conduzir, a condução [...] mas é também a maneira como uma pessoa se conduz, a maneira como se deixa conduzir, a maneira como é conduzida".

No caso da condução das condutas relacionadas ao uso da língua, é possível especificar a noção de governamento linguístico. A adjetivação do conceito de governamento, nesse caso, não imprime novidade conceitual e não passa de uma tentativa de detalhar práticas e conferir foco ao que é possível observar no material analisado, bem como de recortar as possibilidades de análise. Assim, a possibilidade de analisar políticas linguísticas de educação de surdos desde a perspectiva do governamento linguístico permite entendermos que, em determinado sentido, a educação de surdos carrega consigo a responsabilidade primeira de um ensino da língua, sobretudo para produzir formas governáveis de ser surdo.

A ação sobre a ação linguística dos surdos opera também nos seus processos de subjetivação. Ao avançar nos estudos sobre as práticas de governamento modernas, Foucault "percebeu que essas 'coisas do governo' funcionavam bem para descrever, examinar, analisar e problematizar outros modos pelos quais alguém se torna sujeito" (VEIGA-NETO; SARAIVA, 2011, p. 7). Portanto, adotamos tais conceitos, o governamento linguístico e a subjetivação, sob a ótica da matriz de experiência, para desenvolver uma análise em um conjunto de políticas linguísticas identificado em documentos legais que afetam direta ou indiretamente a educação de surdos em Portugal.

\section{Políticas linguísticas de educação de surdos}

Neste artigo, a política linguística também é entendida como a "determinação das grandes decisões referentes às relaçoóes entre as línguas e a sociedade" (CALVET, 2007, p. 11). Para Maher (2010), há uma relação muito estreita entre as políticas linguísticas e as políticas de identidade. Conforme a autora, as políticas linguísticas têm como objetivo não apenas manipular a situação linguística, mas também a identidade étnico-cultural. Essa manipulação está relacionada com a integração de um grupo identitário considerado minoritário no desenvolvimento 
de um país e no fortalecimento da identidade nacional. Conforme Mateus (2011), a tradição monolíngue de Portugal foi posta em causa com o reconhecimento das línguas minoritárias no país, tais como o mirandês e a Língua Gestual Portuguesa (LGP) ${ }^{1}$. Propomos olhar para essas questóes sob a luz do governamento linguístico. Desse modo, destacamos o processo de subjetivação inerente às políticas linguísticas que, por sua vez, possibilitam a constituição de um modo de ser que, dentre outros elementos, é regulado também por uma conduta linguística.

É possível assumir que o governamento linguístico de surdos aconteça desde a emergência de sua educação. Na medida em que, ao longo da sua história, tal educação passa a se institucionalizar, esse tipo de governamento adquire traços mais definidos. Para fins de delimitação espacial e temporal, focamos a análise aqui apresentada numa amostra de políticas linguísticas de educação de surdos em Portugal, possibilitadas pelas pressóes do movimento político da comunidade surda internacional em prol do reconhecimento das línguas de sinais ao redor do mundo a partir da década de 1990. Na Europa, esse reconhecimento deve-se também aos esforços da World Federation of the Deaf (WFD) e da European Union of the Deaf (EUD) (GOMES, 2011). Entretanto, é necessário mencionar que a legitimidade das reivindicaçóes de tais entidades encontrou amparo na crescente formação de saberes sobre a surdez a partir de uma perspectiva sócio-antropológica a partir de 1960. Sign Language Structure (STOKOE, 1960) destaca-se por atribuir um estatuto de língua à comunicação em gestos utilizada pelos surdos nos Estados Unidos da América. Nesse texto, o autor

offers to all those interested in the deaf and their problems solid evidence that the sign, language of the American deaf, unlike such secondary systems as writing or speechreading, has a language-like nature and function. Whether it is a language in the full meaning of the term is a question the linguist ought not to judge until much more evidence of the kind presented here is made available; but the majority of the deaf themselves and many who work with them know that the question was long ago settled pragmatically (STOKOE, 1960, p. 3).

Ao ter sua estrutura estudada a partir de critérios da Linguística, a American Sign Language e outras línguas de sinais pelo mundo passaram a ser reconsideradas na educação de surdos e a eles foi possibilitada a condição de serem pensados não mais apenas como deficientes auditivos, mas também como sujeitos de uma diferença linguística e cultural. Surgiram então os Estudos Surdos como um território de investigaçóes que olham para os surdos, a surdez e a língua gestual desde uma perspectiva sócio-antropológica. Tais investigações foram cruciais no fortalecimento do movimento político dos surdos ao redor do mundo, que reivindica o reconhecimento de suas capacidades linguísticas e de suas especificidades culturais. Para que isso começasse a ser possível, o reconhecimento político das 
línguas de sinais se tornou imperativo, isto é, "the use of Portuguese sign language is not a way of overcoming handicaps - any difficulty deaf students might have in Portuguese spoken language - but a cultural exigency" (CORREIA et al., 2013, p. 18).

No caso de Portugal, o reconhecimento da LGP aconteceu no ano de 1997. No artigo 74, número 2, alínea h) da Constituição da República Portuguesa, ao Estado é designado proteger "e valorizar a língua gestual portuguesa, enquanto expressão cultural e instrumento de acesso à educação e da igualdade de oportunidades" (PORTUGAL, 2005, p. 56). Destacamos aqui o acento no caráter ferramental atribuído à língua gestual, que tem seu reconhecimento constitucional no âmbito de uma expressão cultural e de instrumento de acesso. Nesse caso, evidencia-se a função social da língua no processo de constituição de uma noção de pertença ao Estado. Com isso, não queremos dizer que antes do reconhecimento da LGP, não houvesse estratégias de constituição dessa noção em surdos, como já citado. Tais práticas, entretanto, obedeciam a uma tendência internacional fortemente recomendada em educação de surdos desde 1880: o oralismo.

A formação de saberes sobre o método oral capitaneou a educação de surdos aproximadamente durante cem anos. Esses saberes foram fundamentais para a permanência da manutenção de um comportamento linguístico dos surdos que fosse o mais semelhante possível ao dos ouvintes, e possibilitaram a constituiçẫo de formas de ser surdo pautadas pelo viés da falta, da deficiência e, por consequência, da necessidade educativa especial. Nesse sentido, é compreensível que a LGP náo seja mencionada no Decreto-Lei no 319/91, de 23 de agosto de 1991 (PORTUGAL, 1991). Nesse documento, é aprovado o regime de apoio a alunos com necessidades educativas especiais que frequentam estabelecimentos dos ensinos básico e secundário, de maneira que a escola regular ganha responsabilidade pela educação de alunos com deficiência. Ainda no mesmo texto, é estabelecido que a classificação de diferentes categorias com base na perspectiva médica passa a ser substituída pelo conceito de "necessidade educativa especial" baseado em critérios pedagógicos. $\mathrm{O}$ governamento linguístico dos surdos ainda estava concentrado no uso da língua oral, uma vez que auxiliares acústicos são apontados, no documento, como dispositivos de compensação individual ou de grupo.

Após o reconhecimento da LGP na Constituição, o Despacho $n^{\circ}$ 7.520/98 possibilita, aos surdos, acesso à educação em língua gestual. Ao considerar preceitos da escola democrática e de qualidade, que visa responder "à heterogeneidade social, cultural e linguística" (PORTUGAL, 1998, p. 1) e à constituição de um ambiente escolar "que possibilite o máximo desenvolvimento cognitivo, linguístico, emocional e social" (PORTUGAL, 1998, p. 1), é proposta a educação bilíngue de surdos. Nesse caso, assegura-se, "a nível de ensino, um processo que, simultaneamente, dê acesso ao domínio da língua gestual portuguesa como forma de comunicaçáo privilegiada e ao domínio do português escrito como 
forma de alargamento da comunicaçáo e como instrumento de aprendizagem" (PORTUGAL, 1998, p. 1). Nesse despacho, a LGP é caracterizada como forma de comunicaçâo privilegiada e o português escrito como instrumento de aprendizagem: uma inversão do lugar ocupado pela língua gestual quando ainda era posicionada como um instrumento pedagógico. A língua portuguesa, entretanto, como forma de alargamento da comunicaçâo, permanece essencial em seu papel de língua oficial de uma naçáo e, portanto, porta de acesso à vida em comum no país. Desse modo, o ambiente bilíngue em que a educação de crianças e jovens surdos deve acontecer precisa possibilitar, como consta no texto, "o domínio do português escrito e eventualmente falado, respeitando-se, nessa matéria, as opçóes dos pais no que respeita ao contexto linguístico/educativo em que o seu filho será inserido" (PORTUGAL, 1998, p. 2).

Aqui, nota-se que as formas possíveis de ser surdo, a partir da correlação entre os saberes sobre a surdez e as normativas de comportamento possíveis de observar nas políticas, obedecem a um padrão histórico. Isto é, ainda que línguas de sinais sejam reconhecidas e incorporadas na formação da pessoa surda identificada como pertencente a uma minoria linguística, há sempre a possibilidade de essa pessoa permanecer inscrita no âmbito da deficiência auditiva na medida em que é lembrado que a aprendizagem da língua oral é uma oportunidade para que ela se aproxime, mas não alcance totalmente, a uma normativa do comportamento linguístico ouvinte.

Ao considerar esses esforços de uma educaçáo que começa por se propor bilíngue, o despacho também orienta, no item 6 , as condiçóes para a criação e o funcionamento de unidades de apoio à educação de crianças e jovens surdos em estabelecimentos públicos de ensino básico e secundário. Nesse caso, é apresentada uma proposta de organização da resposta educativa para crianças e jovens surdos que, segundo o documento, "pode ser determinada pelo grau de surdez, pelo nível de desenvolvimento cognitivo, linguístico e social, pela idade e pelo desenvolvimento e participação da família" (PORTUGAL, 1998, p. 3). Destacam-se os subitens $6.2,6.3,6.4$ e 6.5 pelo modo como orientam a realizaçáo do percurso de determinados tipos de alunos surdos:

6.2 - As crianças entre os três e os seis anos devem, preferencialmente, frequentar jardins-de-infância de crianças ouvintes, cumprindo parte do seu programa educativo, em pequeno grupo, nas salas de jardins-de-infância das unidades de apoio à educação de crianças surdas.

6.3 - Os alunos surdos pós-linguísticos realizam, preferencialmente, o seu percurso escolar em turmas de ouvintes, devendo, contudo, evitar-se a sua inserção isolada em turmas de alunos ouvintes.

6.4 - Os alunos surdos pré-linguísticos realizam o seu percurso escolar no $1^{\mathrm{o}}$ ciclo, preferencialmente, em turmas de alunos surdos, de forma a poderem desenvolver e estruturar 
melhor a língua gestual portuguesa e receber todo o ensino nesta língua, sem prejuízo da sua participação com os alunos ouvintes em actividades lúdicas e culturais, bem como áreas curriculares específicas.

6.5 - Os alunos surdos pré-linguísticos que frequentam os $2^{\circ}$ e $3^{\circ}$ ciclos de ensino básico e secundário devem, preferencialmente, estar inseridos em turmas de ouvintes com a presença de um intérprete de língua gestual portuguesa, sempre que os conteúdos curriculares o permitam, podendo também frequentar turmas de alunos surdos sempre que daí resulte maior benefício para o cumprimento do currículo (PORTUGAL, 1998, p. 3).

Independentemente das condiçóes em que se encontra a criança ou o jovem surdo, há a preocupação educativa em resultar um maior benefício e evitar prejuízos na sua formaçáo, considerando, principalmente, critérios relacionados a saberes sobre a sua conduta linguística. Identifica-se, entáo, um uso de saberes sobre a surdez, especificamente saberes atrelados à língua, para regulamentar uma normatividade de comportamentos e instituir os mesmos modos específicos de ser surdo de acordo com cada condição linguística relacionada com a surdez. Essa classificação de formas possíveis de ser surdo pode ser vista na primeira metade do século XX em diferentes países como Holanda, Estados Unidos e Brasil, quando testes de inteligência desenvolvidos pelo médico holandês Dirk Herderschêe serviam para categorizar trajetos educativos para cada tipo de sujeito surdo.

O teste Herderschêe, que é uma adaptação do teste de inteligência Binet-Simon, não exigia um uso da língua e era considerado ideal para a testagem em crianças que, por qualquer razão, não podiam ouvir nem falar, e que "were unable to keep up in an educational setting” (HURKS; BAKKER, 2016, p. 266). No manual produzido por um dos diretores do Instituto Nacional de Educação de Surdos no Brasil nessa mesma época (LACERDA, 1934), o teste Herderschêe serviu de modelo para poder classificar os alunos do instituto como surdos-mudos completos, surdos incompletos, semissurdos propriamente ditos e semimudos. Tais tipos de sujeito receberiam a educação linguística considerada, conforme o manual do diretor, mais adequada à sua classificação: método escrito (sinais gráficos e digitais), método acústico oral (associação dos exercícios acústicos aos orais), método acústico oral ou método oral (exercícios de articulação e leitura labial).

Naquele momento da história da educação de surdos, as formas possíveis e aceitáveis de ser surdo estavam restritas à língua oral e sua modalidade escrita, entretanto a sinalização como parte da conduta linguística dos surdos escapa às estratégias de governamento desses sujeitos e possibilita a constituição de formas resistentes de ser surdo. Uma vez possíveis e existentes tais formas, novos saberes sobre as suas condutas são produzidos e, mais tarde, outras condutas passam a ser previstas em normativas: a diferença é gerida. Com o Decreto-Lei no 3/2008, que revoga o Decreto-Lei no 319/91, são definidas algumas diretrizes para a imple- 
mentação da educação inclusiva em Portugal com base na gestão da diversidade. No documento, é declarado que "a escola inclusiva pressupóe individualização e personalizaçáo das estratégias educativas, enquanto método de prossecuçáo do objectivo de promover competências universais que permitem a autonomia e o acesso à condução plena da cidadania por parte de todos" (PORTUGAL, 2008a, p. 154). A cidadania aceitável e conveniente que antes era atribuída aos surdos por um processo de medicalização (COELHO, 2010), vê-se agora construída por meio de políticas afirmativas de acessibilidade e gestão das diferenças, dentre elas, diferenças linguísticas.

Desse modo, são criadas, por despacho ministerial, as escolas de referência para a educação bilíngue de alunos surdos (EREBAS). Nessas instituiçōes é estabelecido que se possibilite um ambiente que favoreça "o domínio da LGP, o domínio do português escrito e, eventualmente, falado, competindo à escola contribuir para o crescimento linguístico dos alunos surdos, para a adequação do processo de acesso ao currículo e para a inclusão escolar e social" (PORTUGAL, 2008a, p. 159). O surgimento das EREBAS "obriga a escola a uma aceitação de toda uma cultura e não apenas a encontrar estratégias para colmatar as deficiências de cada aluno/a, individualmente, ao abrigo da figura das necessidades educativas especiais" (CORREIA; COELHO, 2014, p. 117). Nas EREBAS ou em instituições educacionais que se ocupam da educação de surdos acontece o encontro entre os surdos. Para Giammelaro, Gesueli e Silva (2013), esse é um fator relevante na constituição da identidade em crianças surdas. O governamento linguístico, entretanto, materializa-se nesse contexto em adequaçóes curriculares ao ensino bilíngue para alunos surdos. Tais adequaçôes consistem na introdução de áreas curriculares específicas para a primeira língua (L1), segunda língua (L2) e terceira língua (L3), determinadas da seguinte forma:

a) A língua gestual portuguesa (L1), do pré-escolar ao ensino secundário;

b) O português segunda língua (L2) do pré-escolar ao ensino secundário;

c) A introduçáo de uma língua estrangeira escrita (L3) do $3^{\circ}$ ciclo do ensino básico ao ensino secundário (PORTUGAL, 2008a, p. 158).

Em relação aos lugares ocupados pelas línguas no currículo da educação bilíngue de surdos constituído pelo documento, Gomes (2011, p. 120) aponta que "o Decreto-Lei no 3/2008 não só consolidou as orientaçóes para uma educação bilíngue, como criou um espaço próprio no currículo para a disciplina de LGP, enquanto primeira língua dos alunos surdos". Assim, os docentes surdos de língua gestual ${ }^{2}$ são responsabilizados pelo desenvolvimento da LGP como primeira língua dos alunos surdos e, aos docentes ouvintes, é atribuída a responsabilidade pelo desenvolvimento da língua portuguesa como segunda língua dos alunos sur- 
dos (PORTUGAL, 2008a). Do mesmo modo, são atribuídos, aos agrupamentos de escolas e escolas secundárias, os seguintes objetivos:

a) Assegurar o desenvolvimento da LGP como primeira língua dos alunos surdos; b) Assegurar o desenvolvimento da língua portuguesa escrita como segunda língua dos alunos surdos; c) Assegurar às crianças e jovens surdos, os apoios ao nível da terapia da fala (PORTUGAL, 2008a, p. 161).

Observa-se o esforço do Estado para garantir que qualquer possibilidade de governar linguisticamente as formas de ser surdo encontre respaldo na lei que, por sua vez, está amparada por saberes linguísticos, médicos e educacionais sobre a surdez e os surdos: o que reforça a análise a partir da matriz de experiência.

Os Decretos-Leis no 54/2018 e no 55/2018 (PORTUGAL, 2018a; 2018 b), por estabelecerem, respectivamente, o regime jurídico da educação inclusiva (PORTUGAL, 2018a) e o currículo dos ensinos básico e secundário, bem como os princípios orientadores da avaliação das aprendizagens (PORTUGAL, 2018b), merecem ser discutidos.

No Decreto-Lei no 54/2018 (PORTUGAL, 2018a), os aspectos linguísticos da educação de surdos se encontram diluídos e não explicitados em meio a um conjunto de terminologias da educação inclusiva, tais como acomodaçôes curriculares, adaptaçôes curriculares não significativas e significativas, áreas curriculares especificas, barreiras de aprendizagem, intervenção precoce na infância, plano individual de transição, programa educativo individual etc. Assim, as escolas de referência para a educação bilíngue são mencionadas como recursos organizacionais específicos de apoio à aprendizagem e à inclusão e as condiçôes linguísticas desse modelo educacional, entretanto, aparecem brevemente elencadas em seu art. 15, reproduzindo o posicionamento da língua gestual portuguesa e da língua portuguesa escrita, respectivamente, como L1 e L2. No mesmo artigo, terapeutas da fala figuram como profissionais que integram esse recurso organizacional, ao lado de docentes com formação especializada em educação especial na área da surdez e de docentes e intérpretes de LGP.

Em relação ao Decreto-Lei no 55/2018 (PORTUGAL, 2018b), esses aspectos são menos explorados ainda. Em seu art. $6^{\circ}$, sobre a finalidade de garantir um currículo no qual todos os alunos, independentemente da oferta educativa e formativa que frequentem, alcancem competências definidas pelo Perfil de Alunos à Saída da Escolaridade Obrigatória, é mencionado o acesso "à oferta da disciplina de Português Língua não Materna a alunos cuja língua materna não é o Português, bem como o Português Língua Segunda para alunos surdos" (PORTUGAL, 2018b, p. 2931). No entanto, a língua gestual nem mesmo é mencionada em todo o documento. Observa-se que tanto o Decreto-Lei no 54/2018 quanto o 
no 55/2018 (PORTUGAL, 2018a; 2018b) apresentam recorrências que também estâo nos últimos documentos que os antecedem.

É possível observar que esses dois mais recentes documentos não acrescentam alterações ao funcionamento das EREBAS, mas também não incidem nem destacam os princípios e os fundamentos da educação bilíngue para surdos, como na legislação que os antecede. Nota-se, aí, uma noção abrangente de inclusão, que proporciona uma condição esmaecida às singularidades linguísticas e culturais da experiência da surdez, isto é, às diferenças. Nesse caso, vemos um aperfeiçoamento das estratégias de governamento exercidas pelo Estado, que se tornam mais sutis e aumentam as possibilidades do seu alcance.

É importante destacar que, entretanto, tais esforços não necessariamente correspondem à materialidade das práticas escolares em Portugal, nem mesmo à totalidade das formas de ser surdo no país e pelo mundo. Sobre esse aspecto a ser considerado em qualquer análise de legislação, vale ressaltar que os "contornos das práticas não dependem exclusivamente dos articulados legais" (COELHO, 2010, p. 46). Este estudo, contudo, intentou evidenciar náo tanto o que se produz em termos de subjetivação dos surdos, mas muito mais o que essa racionalidade almeja na produção de formas possíveis de ser surdo em Portugal - e que podem ser observadas em qualquer outro país - , sobretudo a partir da arquitetura de suas condutas linguísticas. Além disso, é importante que se considere que tais políticas resultam de esforços não apenas políticos, mas também acadêmicos e sociais (SANTOS; COELHO; KLEIN, 2017). Esses esforços, é preciso destacar, constituem-se a partir de tendências e redes internacionais.

\section{Considerações finais}

A constituição dos modos de ser surdo na Contemporaneidade não acontece de uma única forma: os aspectos que formam o ethos surdo transitam entre a anormalidade, a diferença, a deficiência, a expressão cultural, entre outros que podem constituir um mesmo indivíduo (LOPES; THOMA, 2013). Neste artigo, o nosso objetivo foi explicitar como essa constituição é estruturada a partir de políticas linguísticas de educação de surdos que propóem governar a conduta linguística de surdos em Portugal. Ainda que o recorte de políticas analisado compreenda Portugal e apresente particularidades nacionais, a educação de surdos, o movimento político dos surdos e a produção acadêmica sobre a surdez têm se organizado internacionalmente. Rocha (2016) apresenta evidências históricas de que os principais institutos de educação de surdos ao redor da Europa e das Américas desenvolveram uma intensa comunicação desde o século XVIII, o que permite entender a educação de surdos numa rede histórica. Ao realizarmos a análise desse material desde a perspectiva da surdez como uma matriz de experiência, identificamos que tais políticas constituem normativas do comportamento linguístico 
dos surdos que são sustentadas por saberes sobre a surdez. Nessa relação vista em tais políticas, é possível observar, portanto, a constituição de formas universais possíveis de ser surdo.

É preciso reforçar que a governamentalização das condutas humanas não pode ser interpretada unicamente como uma prática negativa, pois o governamento proporciona eficiência na gestão das sociedades. É importante ponderar que, como todas as formas de poder, as técnicas do governamento "são paradoxais: podem ajudar, mas também podem manipular; podem cuidar, mas também podem criar dependências; podem orientar, mas também podem submeter às vontades" (RUIZ, 2016, p. 24). Além disso, destacamos que as estratégias de governamento, por mais longo que seja o seu alcance, permanecem suscetíveis ao escape das formas de ser.

Como foi possível perceber a partir do estudo aqui apresentado, as estratégias de governamento linguístico identificadas no conjunto de políticas analisado têm considerado, de maneira ampla, as possibilidades de conduzir a conduta linguística dos surdos. Proliferam as normartivas para educá-los através de uma língua ou de outra sem perder de vista a preocupação com o maior aproveitamento das suas respostas educativas. Já o ensino da língua oral na sua modalidade escrita ou falada e o ensino de uma língua de sinais agora assumidamente nacional, o que evidencia o propósito nacionalizador, encontram-se diluídos num conjunto de práticas que oferecem condições para a formação de uma forma de vida surda com características cosmopolitas. Entendemos, portanto, que tal proliferação permanece oferecendo os mesmos modelos para a constituição de formas de ser surdo que reforçam a célebre desterritorialização da surdez sobre a qual já escreveu Wrigley (1996).

\section{Notas}

1. Em Portugal, os sistemas linguísticos de natureza visual-motora oriundos de comunidades surdas são tratados como línguas gestuais. Neste artigo, utilizamos o termo empregado na variação brasileira da língua portuguesa, línguas de sinais, para se referir a essas línguas no coletivo; e reservamos o uso de língua gestual para fazer referência à língua de sinais utilizada em Portugal.

2. Na Lei no 21/2008, a designaçáo docente surdo de LGP é alterada para docente de LGP.

\section{Referências}

BERENBLUM, A. A invençáo da palavra oficial: identidade, língua nacional e escola em tempos de globalização. Belo Horizonte: Autêntica, 2003.

BURKE, P. A arte da conversaçáo. São Paulo: Editora da Universidade Estadual Paulista, 1995. 
CALVET, L. As políticas linguísticas. São Paulo: Parábola Editorial; IPOL, 2007.

CASTRO, E. Vocabulário de Foucault: um percurso pelos seus temas, conceitos e autores. Belo Horizonte: Autêntica, 2009.

COELHO, O. Surdez, educação e cidadania. Duas línguas para um caminho e para um mundo. In: COELHO, O. (org.). Um copo vazio está cheio de ar: assim é a surdez. Porto: Livpsic, 2010. p. 17-100.

CORREIA, F.; COELHO, O. Revolução de Abril, educação de surdos/as e ensino da Filosofia: da deficiência à pertença cultural. Educaçáo, Sociedade \& Culturas, Porto, n. 43, p. 103-119, 2014.

CORREIA, F.; COELHO, O.; MAGALHÃES, A.; BENVENUTO, A. Learning/ Teaching Philosophy in Sign Language as a cultural issue. Journal of Education Culture and Society, Wroclaw, n. 1, p. 9-19, 2013. http://doi.org/10.15503/ jecs20131-9-19

DAVIS, L. Enforcing normalcy: disability, deafness, and the body. Londres; Nova York: Verso, 1995.

DIZEU, L. C. T. B.; CAPORALI, S. A. A língua de sinais constituindo o sujeito surdo. Educação \& Sociedade, Campinas, v. 26, n. 91, p. 583-597, ago. 2005. http://dx.doi. org/10.1590/S0101-73302005000200014

FOUCAULT, M. O governo de si e dos outros. Curso no Collège de France (19821983). São Paulo: Martins Fontes, 2010.

FOUCAULT, M. O retorno da moral. In: FOUCAULT, M. Ética, sexualidade, política. Ditos e escritos V. 2. ed. Rio de Janeiro: Forense Universitária, 2006. p. 252-263.

FOUCAULT, M. Segurança, território, populaçáo: curso dado no Collège de France (1977-1978). São Paulo: Martins Fontes, 2008.

GIAMMELARO, C. N. F.; GESUELI, Z. M.; SILVA, I. R. A relação sujeito/linguagem na construção da identidade surda. Educaçáo \& Sociedade, Campinas, v. 34, n. 123, p. 509-527, jun. 2013. http://dx.doi.org/10.1590/S0101-73302013000200011

GOMES, M. A reconfiguração política da educação de surdos. Indagatio Didactica, Aveiro, v. 3, n. 1, p. 109-125, fev. 2011.

HURKS, P.; BAKKER, H. Assessing intelligence in children and youth living in the Netherlands. International Journal of School \& Educational Psychology, Filadélfia, v. 4, n. 4, p. 266-275, abr. 2016. https://doi.org/10.1080/21683603.2016.1166754

LACERDA, A. Pedagogia Emendativa do Surdo-Mudo: consideraçóes gerais. Rio de Janeiro: Pimenta de Mello \& Cia., 1934.

LOPES, M. C.; THOMA, A. S. Subjectivation, normalisation et constitution de l'éthos sourd: politiques publiques et paradoxes contemporains. La Nouvelle Revue de Ladaptation et de la Scolarisation, n. 64, p. 105-116, 2013. https://doi.org/10.3917/ $\underline{\text { nras.064.0105 }}$ 
MAHER, T. Políticas linguísticas e políticas de identidade: currículo e representaçóes de professores indígenas na Amazônia ocidental brasileira. Currículo sem Fronteiras, v. 10, n. 1, p. 33-48, jun. 2010. Disponível em: <http://www.curriculosemfronteiras.org/ vol10iss1articles/maher.pdf $>$. Acesso em: 22 abr. 2018.

MATEUS, M. Diversidade linguística na escola portuguesa. Revista Lusófona de Educaçáo, Lisboa, v. 18, n. 18, p. 13-24, 2011.

PORTUGAL. Constituição da República Portuguesa. Sétima Revisão Constitucional. Lisboa: República Portuguesa, 2005.

PORTUGAL. Decreto-Lei no 3, de 7 de janeiro de 2008. Define os apoios especializados a prestar na educação pré-escolar e nos ensinos básico e secundário dos sectores público, particular e cooperativo. Diário da República, Lisboa, n. 4, p. 1-15, 7 jan. 2008a.

PORTUGAL. Decreto-Lei no 54, de 6 de julho de 2018. Estabelece o regime jurídico da educação inclusiva. Diário da República, Lisboa, n. 129, p. 2918-2928, 6 jul. 2018 a.

PORTUGAL. Decreto-Lei no 55, de 6 de julho de 2018. Estabelece o currículo dos ensinos básico e secundário e os princípios orientadores da avaliação das aprendizagens. Diário da República, Lisboa, n. 129, p. 2928-2943, 6 jul. 2018 b.

PORTUGAL. Decreto-Lei no 319, de 23 de agosto de 1991. Aprova o regime de apoio a alunos com necessidades educativas especiais que frequentem estabelecimentos do ensino básico e secundário. Diário da República, Lisboa, n. 193, p. 4389-4393, 23 ago. 1991.

PORTUGAL. Despacho no 7.520/98 dos Gabinetes dos Secretários de Estado da Administraçáo Educativa e da Educaçáo e Inovaçáo. Lisboa: Ministério da Educaçáo, 1998.

PORTUGAL. Lei no 21, de 12 de maio de 2008. Primeira alteração, por apreciação parlamentar, ao Decreto-Lei n. ${ }^{\circ} 3 / 2008$, de 7 de janeiro, que define os apoios especializados a prestar na educação pré-escolar e nos ensinos básico e secundário dos sectores público, particular e cooperativo. Diário da República, Lisboa, n. 91, p. 25192521, 12 maio 2008b.

ROCHA, S. A educação de surdos em rede internacional: análise de fontes documentais dos séculos XVIII, XIX e XX. In: CONGRESSO LUSO-BRASILEIRO DA HISTÓRIA DA EDUCAÇÃO, 11., 2016, Porto. Anais [...]. Porto: Faculdade de Letras da Universidade do Porto, 2016. p. 116-128.

RUIZ, C. O poder pastoral, as artes de governo e o estado moderno. Cadernos IHU Ideias, São Leopoldo, v. 14, n. 241, 2016.

SANTOS, A. N.; COELHO, O.; KLEIN, M. Educação de surdos no Brasil e Portugal: políticas de reconhecimento linguístico, bilinguismo e formação docente. Educaçáo e Pesquisa, São Paulo, v. 43, n. 1, p. 216-228, jan./mar. 2017. http://dx.doi.org/10.1590/ $\underline{\text { s1517-9702201608148639 }}$

STOKOE, W. Sign language structure: an outline of the visual communication systems of the American Deaf. Buffalo: Universidade de Buffalo, 1960. (Studies in Linguistics: Occasional Papers, n. 8). 
VEIGA-NETO, A.; SARAIVA, K. Educar como arte de governar. Currículo sem Fronteiras, v. 11, n. 1, p. 5-13, jun. 2011. Disponível: $\leq$ http://www.curriculosemfronteiras. org/vol11iss1articles/veiga-neto-saraiva.pdf $>$. Acesso em: 22 abr. 2018.

WITCHS, P. H.; LOPES, M. C. Educação de surdos e governamentalidade linguística no Estado Novo (Brasil, 1934-1948). História da Educaçáo, Porto Alegre, v. 19, n. 47, p. 175-195, 2015a. http://dx.doi.org/10.1590/2236-3459/45771

WITCHS, P. H.; LOPES, M. C. Surdez como matriz de experiência. Revista Espaço, Rio de Janeiro, n. 43, p. 31-47, jan./jun. 2015b. https://doi.org/10.20395/re.v0i43.4

WRIGLEY, O. The Politics of Deafness. Washington, D.C.: Gallaudet University Press, 1996.

\section{SOBRE OS AUTORES}

Pedro Henrique Witchs é doutor em Educação. Professor do Departamento de Línguas e Letras e do Programa de Pós-Graduação em Linguística da Universidade Federal do Espírito Santo (UFES).

Maura Corcini Lopes é doutora em Educação. Professora da Escola de Humanidades e do Programa de Pós-Graduação em Educação da Universidade do Vale do Rio dos Sinos (UNISINOS).

Orquídea Coelho é doutora em Ciências da Educação. Professora da Faculdade de Psicologia e de Ciências da Educação da Universidade do Porto.

Recebido em 03 de junho de 2018.

Aceito em 21 de março de 2019. 